\title{
Notes
}

\section{Record Long-distance Movement of a Deer Mouse, Peromyscus maniculatus, in a New England Montane Boreal Forest}

\author{
CONNOR M. WOOD ${ }^{1,3}$ and SHAWn T. MCKINNEY ${ }^{2}$ \\ ${ }^{1}$ Maine Cooperative Fish and Wildlife Research Unit, Department of Wildlife, Fisheries, and Conservation Biology, University \\ of Maine, Orono, Maine 04469 USA \\ ${ }^{2}$ United States Geological Survey, Maine Cooperative Fish and Wildlife Research Unit, Department of Wildlife, Fisheries, and \\ Conservation Biology, University of Maine, Orono, Maine 04469 USA \\ ${ }^{3}$ Corresponding author: connor.wood@maine.edu
}

Wood, Connor M., and Shawn T. McKinney. 2015. Record long-distance movement of a Deer Mouse, Peromyscus maniculatus, in a New England montane boreal forest. Canadian Field-Naturalist 129(2): 181-182.

We report a single-season, non-homing movement of $4287 \pm 10 \mathrm{~m}$ by an adult male Deer Mouse, Peromyscus maniculatus, in western Maine, United States, in summer 2014. The movement was achieved in two stages: $927 \pm 3 \mathrm{~m}$ in four days and an additional $3360 \pm 10 \mathrm{~m}$ in 44 days. This is approximately $40 \%$ greater than the previously documented maximum linear movement for an individual of this species.

Key Words: Deer Mouse; dispersal; Maine; movement; Peromyscus maniculatus

Although rare, long-distance movements can have major positive and negative impacts on biological communities (Trakhtenbrot et al. 2005). They also offer insight into fundamental ecological patterns, population genetic structuring, and metapopulation dynamics (Bowman et al. 2002; Trakhtenbrot et al. 2005). Documenting such movements, even for common species, is thus an important task. In this note, we report the longest Deer Mouse (Peromyscus maniculatus) movement on record.

The movement took place in summer 2014 along Bigelow Mountain, an approximately 19-km east-west ridgeline in western Maine, United States. The ridgeline is dominated by spruce-fir boreal forest (Picea rubens Sargent and Abies balsamea (L.) Miller), but individual peaks are characterized by alpine tundra. The ridgeline is traversed by the Appalachian Trail and managed as an ecological reserve; aside from two campsites, human impact is minimal. There are no major natural or anthropogenic barriers to dispersal.

Individual locations of Deer Mice were documented using a combination of live and lethal trapping during a larger study of small-mammal community ecology. High-elevation trapping efforts occurred on Avery Peak $\left(1246 \mathrm{~m}\right.$ above sea level; $\left.45.15^{\circ} \mathrm{N}, 70.27^{\circ} \mathrm{W}\right)$ and West Peak (1265 $\mathrm{m}$ above sea level; $\left.45.15^{\circ} \mathrm{N}, 70.29^{\circ} \mathrm{W}\right)$. Sherman Live Traps (Sherman Trap Co., Tallahassee, Florida, USA) were laid out in $90 \mathrm{~m} \times 90 \mathrm{~m}$ grids $(10$ rows of 10 traps spaced $10 \mathrm{~m}$ apart), baited with oats and peanuts, and supplied with cotton balls for nesting material. Trap locations were recorded with a Global Positioning System (GPS) unit (GPSMAP 62s, Garmin, Olathe, Kansas, USA) with a location accuracy of $\pm 3 \mathrm{~m}$.
Traps were checked each morning and evening for three days, and the morning of a fourth day. All captures were identified to species, given a uniquely numbered ear tag (Monel \#1, Kentucky Band and Tag Co., Newport, Kentucky, USA), weighed, sexed, measured, and marked by taking a small hair clipping before release. Distances were measured using Garmin BaseCamp (Garmin) and represent direct Euclidean movement.

An adult male Deer Mouse, tagged as 923, was captured five times on four consecutive days (9-12 June) on Avery Peak (grid 1). His maximum detected movement within grid 1 was $30 \pm 3 \mathrm{~m}$. Four days later (June 16) and $927 \pm 3$ m west, mouse 923 was captured on West Peak (grid 2). This first major movement occurred between 1000 on 12 June and 0800 on 16 June, which required a minimum movement of approximately $232 \mathrm{~m} /$ day. In ten weeks of trapping in 15 grids, this was the only instance where we detected an individual moving between trapping grids.

Mouse 923 was subsequently captured five times on four consecutive days (16-19 June) on grid 2. Maximum detected movement within grid 2 was $22 \pm 3 \mathrm{~m}$. Forty-four days after his last capture in grid 2, mouse 923 was lethally trapped on 2 August by an Appalachian Trail caretaker at Horns Pond $(964 \mathrm{~m}$ above sea level; $\left.45.14^{\circ} \mathrm{N}, 70.33^{\circ} \mathrm{W}\right), 3360 \pm 10 \mathrm{~m}$ west of his last known location in grid 2 . That suggests a mean minimum movement of $76 \mathrm{~m} /$ day over this last period, although the distance and duration of his first major longdistance movement indicates that he could have moved much more quickly. In 51 days after his last capture in grid 1 , mouse 923 moved $4287 \pm 10 \mathrm{~m}$ west along the Bigelow ridgeline. This movement exceeds the previ- 
ous movement record for this species by $1243 \mathrm{~m}$ (Jung et al. 2005).

We are confident that the mouse tagged as 923 at grid 2 is the same as the one found in grid 1 for several reasons. First, to our knowledge, no other small mammal research has been conducted in that region of Maine in at least the last five years. Therefore, it is unlikely that an animal tagged by a different researcher could have reached our trap grid. Second, mouse 923 had a distinctive area of clipped fur along his flank, unequivocal evidence that our team had previously captured him. Third, we captured mouse 923 five times in grid 2, allowing us ample opportunity to verify that we had correctly read the tag.

During our time in grids 1 and 2, we spent several evenings conversing with the Appalachian Trail caretaker who lived on the mountain. On 4 August, he reported that, two days earlier, he had killed a number of mice near his cabin and noticed that one of them was wearing ear tag 923 . He disposed of the carcass before we could verify the identity. However, given mouse 923's established propensity for rapid long distance movements $(927 \pm 3 \mathrm{~m}$ in five days between grids 1 and 2), the absence of other sources of tagged animals, the caretaker's familiarity with the project, the lack of plausible means for assisted movement, and the numerous previous instances of long-distance movements by this species (Bowman et al. 1999; Jung et al. 2005), we are confident that the mouse lethally trapped and reported as Deer Mouse 923 was indeed the same individual that we captured in grids 1 and 2 .

This $4287 \pm 10 \mathrm{~m}$ single-season, non-homing movement by an adult male Deer Mouse exceeds movements of $3044 \pm 60 \mathrm{~m}$ and $1768 \mathrm{~m}$ reported by Jung et al. (2005) and Bowman et al. (1999) in similar habitat. Both Jung et al. (2005) and Bowman et al. (1999) reported long-distance movements of subadult male Deer Mice in autumn that were presumed to be dispersal from natal range. The observation of Bowman et al. (1999) coincided with a large-scale irruption of Deer Mice (Bowman et al. 2001).

We detected no evidence of irruptive dynamics (C. M. Wood and S. T. McKinney, unpublished data), suggesting that density-dependent factors did not influence the long-distance movement recorded at our study site. The mass $(19.5 \mathrm{~g})$ and snout to vent length $(7.5 \mathrm{~cm})$ of mouse 923 were in the third quartile for all Deer Mice captured that summer $(N=143$, Wood and McKinney unpublished data), suggesting that size alone would not have made him a social subordinate. Fairbairn (1978) suggested that some Deer Mice display an innate propensity for dispersal regardless of social pressure and are distinguishable from their peers only by elevated levels of spontaneous activity. We have no data on mouse 923's relative level of spontaneous activity, but his overall movements revealed a pattern of two four-day periods with short, localized movements (22$30 \pm 3 \mathrm{~m}$ ), punctuated by major directional movement $(927 \pm 3 \mathrm{~m})$. This pattern suggests a dynamic interplay between localized foraging behaviour and a strong innate tendency toward movement. It corroborates the increasingly well-documented vagility of small mammals (Bowman et al. 1999; Maier 2002; Rehmeier et al. 2004; Jung et al. 2005), which could be a key attribute for population connectivity at broader spatial scales.

\section{Acknowledgements}

We thank A. Black for assistance in the field, I. Fitzmorris for documenting the final location of mouse 923, and T. Divoll and two anonymous reviewers for their comments. We thank the Maine Department of Agriculture, Conservation, and Forestry, Bigelow Preserve, for allowing us access to conduct research and for logistical support. This research was funded by the Maine Outdoor Heritage Fund (project 141-01-04), the Maine Cooperative Fish and Wildlife Research Unit, and the University of Maine Graduate Student Government. This research was conducted under the approved University of Maine Institutional Animal Care and Use Committee protocol number A2014-04-03. Mention of trade names and commercial products does not constitute endorsement or recommendation for use by the United States government.

\section{Literature Cited}

Bowman, J. C., M. Edwards, L. S. Sheppard, and G. J. Forbes. 1999. Record distance for a non-homing movement by a Deer Mouse, Peromyscus maniculatus. Canadian Field-Naturalist 113: 292-293.

Bowman, J., G. J. Forbes, and T. G. Dilworth. 2001. Spatial and temporal patterns of an irrupting population of Deer Mice. Journal of Mammalogy 82: 567-572.

Bowman, J. C., J. A. G. Jaeger, and L. Fahrig. 2002. Dispersal distance of mammals is proportional to home range size. Ecology 83: 2049-2055.

Fairbairn, D. J. 1978. Behaviour of dispersing Deer Mice (Peromyscus maniculatus). Behavioral Ecology and Sociobiology 3: 265-282.

Jung, T. S., K. S. O'Donovan, and T. Powell. 2005. Longdistance movement of a dispersing deer mouse, Peromyscus maniculatus, in the boreal forest. Canadian Field-Naturalist 119: 451-452.

Maier, T. J. 2002. Long-distance movements by female White-footed Mice, Peromyscus leucopus, in extensive mixed-wood forest. Canadian Field-Naturalist 116: 108111.

Rehmeier, R. L., G. A. Kaufman, and D. W. Kaufman. 2004. Long-distance movements of the deer mouse in tallgrass prairie. Journal of Mammalogy 85: 562-568.

Trakhtenbrot, A., R. Nathan, G. Perry, and D. M. Richardson. 2005. The importance of long-distance dispersal in biodiversity conservation. Diversity and Distributions 11 : 173-181.

Received 21 October 2014

Accepted 14 March 2015 